\title{
NECESSITY OF ROUTINE HISTOPATHOLOGICAL EXAMINATION OF GALL BLADDER SPECIMENS AFTER ELECTIVE CHOLECYSTECTOMY: AN EXPERIENCE AT TERTIARY CARE HOSPITAL OF SOUTHERN PUNJAB PAKISTAN.
}

\footnotetext{
1. M.Phil (Morbid Anatomy and Histopathology)

Assistant Professor Pathology Quaid-e-Azam Medical College, Bahawalpur.

2. MBBS, FCPS (Medicine) Senior Registrar Bahawal Victoria Hospital, Bahawalpur.

3. MBBS, M.Phil (Morbid Anatomy and Histopathology) Assistant Professor Pathology Sahiwal Medical College, Sahiwal. 4. MBBS

House Officer

Mayo Hospital, Lahore.
}

Correspondence Address:

Dr. Sadaf Shafique

Department of Pathology

Quaid-e-Azam Medical College,

Bahawalpur.

drsadafshafiq@gmail.com

Article received on:

24/06/2019

Accepted for publication:

$12 / 10 / 2019$

\begin{abstract}
Sadaf Shafique', Raheel Khan², Raees Abbas ${ }^{3}$, Bakhtawer Mehmood ${ }^{4}$
ABSTRACT... Objectives: Few centers adopt a selective approach in sending these specimens to pathology department for histopathology whereas it is a routine procedure in our setup. In our study, few unexpected cases of adenocarcinoma of gall bladder were seen during investigation of results of pathological examination of gall bladder specimens. Study Design: Cross sectional study. Setting: Department of Pathology, Quaid-e-Azam Medical College/Bahawal Victoria Hospital Bahawalpur. Period: $1^{\text {st }}$ January 2018 to $31^{\text {st }}$ December 2018. Material \& Methods: The demographic properties of the patients were evaluated from the past records and their association was seen with the histopathological diagnosis and frequency of unexpected cases of gall bladder carcinoma. Results: Total of 840 cases were reviewed with mean age of the patient $42.48 \pm 14.8$ years. The most frequent diagnosis was chronic cholecystitis with cholelithiasis $(n=806)$ which was associated with upper abdominal pain $(p<0.01)$. It was more prevalent among female sex $(n=742)$. Six patients $(0.7 \%)$ showed evidence of adenocarcinoma of gall bladder which had no gross abnormality on macroscopic examination. Conclusion: It is very significant to do routine histopathological examination of all the gall bladder specimens removed for benign diseases during elective cholecytectomies which incidentally may also be associated with carcinoma gall bladder and may require further surgical intervention.
\end{abstract}

Key words: Adenocarcinoma, Cholecystectomy, Cholelithiasis, Demographic, Histopathological, Macroscopic Examination.

Article Citation: Shafique S, Khan R, Abbas R, Mehmood B. Necessity of routine histopathological examination of gall bladder specimens after elective cholecystectomy: An experience at Tertiary Care Hospital of Southern Punjab Pakistan. Professional Med J 2020; 27(6):1171-1175.

DOI: 10.29309/TPMJ/2020.27.06.3846

\section{INTRODUCTION}

Gall bladder diseases are one of the major health problems emerging in our developing country, Pakistan. The incidence of gall bladder stones is on a continuous rise particularly due to the sedentary lifestyles, increase in calorie intake and fat consumption and decrease in fiber intake. ${ }^{1}$ Although the gall stone disease is benign and the procedure of cholecystectomy has very less morbidity associated with it but still gall stones are major risk factors for the development of gall bladder carcinoma. ${ }^{2}$ It becomes even more dangerous if gall stones have remained silent through many years. ${ }^{3}$

Therefore the disposal of the gall bladder specimens without doing histopathology is best to be avoided. The approach of sending only selective gall bladder specimens to the laboratory may result in missing of many important pre malignant lesions such as porcelain gall bladder, carcinoma in situ and development of early carcinomas. $^{4,5}$ Early stages of carcinoma of gall remain undiagnosed if histopathology of these specimens is not done as neither any clinical signs and symptoms are produced nor are any lesions seen on ultrasound. The procedure of cholecystectomy performed for benign diseases based on clinical, ultrasound, and computerized tomographic scanning misses a large number of critical early malignant lesions of gall bladder. So in order to avoid such detrimental mistakes every cholecystectomy specimen should be sent for routine histopathological examination. ${ }^{6}$ 
Carcinoma of gall bladder is although rare but still it is one of the most life threatening malignancy affecting biliary tract. ${ }^{7}$ Women are mostly affected as compared to men with its peak incidence occurring in $6^{\text {th }}$ and $7^{\text {th }}$ decades of life. ${ }^{8}$ It is most common underlying pathology in patients who have undergone cholecystectomy with provisional diagnosis of chronic cholecystitis with cholelithiasis and long standing inflammation due to gall bladder stones is an important etiology for development of carcinoma. ${ }^{9}$ The incidence of presence of adenocarcinomas is approximately $0.3-12 \%$ in gall bladder specimens with initial diagnosis of gall bladder stones..$^{10}$ Approximately $10 \%$ of the other cases may also show metaplasia, hyperplasia, dysplasia and carcinoma in situ which are known pre malignant lesions of gall bladder carcinoma. Histopathological analysis is therefore necessary for the diagnosis of early carcinomas with incidental finding of stage 1 diseases having a very good prognosis. ${ }^{11}$

In most tertiary care hospitals it is a common practice to discard the gall bladder specimens on the pretext that surgeons found them fine on mere gross examination or sending them to laboratory may cause extra financial burden and workload for pathologists. So histopathology is only confined to those which are found as grossly abnormal. Whereas this practice is totally contradicted in rest of the world where all the gall bladder specimens are being sent for histological analysis for identification of even discrete carcinomas in early stage.

The aim of this retrospective analysis was to describe the necessity of performing histopathological analysis in every gall bladder specimen to ensure diagnosis of discrete carcinoma of gall bladder which can markedly decrease the mortality associated with it.

\section{MATERIAL \& METHODS}

A retrospective histopathological analysis of all the gall bladder specimens obtained after cholecystectomy whether performed open or laproscopic for benign diseases of gallbladder, from January 2018 to December 2018 was carried out in the Department of Pathology Quaid-e-
Azam Medical College/Bahawal Victoria Hospital, Bahawalpur. The study consisted of 840 patients with acute or chronic cholecystitis secondary to gall stones admitted through outpatient department. This research was conducted according to the principles of the declaration. Patients of both sexes and all age groups were included in the study. Those patients having evident signs of malignancy on radiological imaging were excluded. Gall bladders which showed gross abnormalities suggesting malignancy during surgical procedures were also excluded from the study. Patients' personal data including the demographics, operation findings, pathology results and stage of cancer cases were obtained from the patients' records. Histological findings are based on haemotoxylin and eosin stained slides in a standard way. The biopsy reports were also obtained from the previous records available in the pathology department. Pathological examination results were categorized as chronic cholecystitis with cholelithiasis, acute cholecystitis with mucocele, acute cholecystitis with empyema, polyp and malignancy. Data was entered into SPSS version 23 and analyzed.

\section{RESULTS}

Over a period of one year 840 patients with symptomatic gall stones were admitted for cholecystectomy. There were 768 females and 72 males with male to female ratio of 1:10.6 (Table-I). The age ranged from 13 to 87 years with the mean age of $42.48 \pm 14.8$ years (Table-II) Majority of patients had presented with the complaint of variable duration of diffuse upper abdominal pain. Other symptoms also shown in Table-III. On stratification of effect modifiers statistical significance was found in increased frequency of chronic cholecystitis with cholelithiasis in female patients (Table-IV) and increased frequency of upper abdominal pain symptom in patients with chronic cholecystitis with cholelithiasis $(p<0.01)$ (Table-V). However, most statistical significance was seen in different age groups.

Of all 840 gall bladder specimens sent for histopathology, eight hundred and six of the specimens showed evidence of chronic cholecystitis with cholelithiasis, 16 with acute 
cholecystitis with mucocele, 11 with acute cholecystitis with empyema and 1 with incidental finding of polyp. Six gall bladders (0.7\%) showed evidence of adenocarcinoma of variable histology but grossly they showed no gross abnormalities.

\begin{tabular}{|l|c|c|}
\hline & Frequency & Percent \\
\hline Male & 72 & 8.6 \\
\hline Female & 768 & 91.4 \\
\hline Total & 840 & 100.0 \\
\hline
\end{tabular}

Table-I. Frequency of patients according to gender

\begin{tabular}{|l|c|c|}
\hline & Frequency & Percent \\
\hline 13- 25 years & 78 & 9.3 \\
\hline 26-49 years & 502 & 59.8 \\
\hline 50 years and above & 260 & 31.0 \\
\hline Total & 840 & 100.0 \\
\hline
\end{tabular}

Table-II. Age distribution

\begin{tabular}{|l|c|c|}
\hline & Frequency & Percent \\
\hline Pain in upper abdomen & 766 & 91.2 \\
\hline Intolerance to fatty food & 40 & 4.8 \\
\hline Nausea and/or vomiting & 31 & 3.7 \\
\hline Mass in right hypochondrium & 3 & .4 \\
\hline Total & 840 & 100.0 \\
\hline
\end{tabular}

Table-III. Presenting symptoms

\begin{tabular}{|c|c|c|c|c|c|}
\hline & & \multicolumn{2}{|c|}{ Gender } & \multirow{2}{*}{ Total } & \multirow{2}{*}{ P-Value } \\
\hline & & Male & Female & & \\
\hline \multirow{5}{*}{ Diagnosis } & Chronic cholecystitis with cholelithiasis & 64 & 742 & 806 & \multirow{6}{*}{$<0.001$} \\
\hline & Acute cholecystitis with mucocele & 2 & 14 & 16 & \\
\hline & Acute cholecystitis with empyema & 4 & 7 & 11 & \\
\hline & Polyp & 1 & 0 & 1 & \\
\hline & Malignancy & 1 & 5 & 6 & \\
\hline \multicolumn{2}{|l|}{ Total } & 72 & 768 & 840 & \\
\hline
\end{tabular}

\begin{tabular}{|c|c|c|c|c|c|c|c|}
\hline & \multicolumn{4}{|c|}{ Presenting symptoms } & \multirow[b]{2}{*}{ Total } & \multirow[b]{2}{*}{ P-value } \\
\hline & & $\begin{array}{l}\text { Pain in upper } \\
\text { abdomen }\end{array}$ & $\begin{array}{l}\text { Intolerance to } \\
\text { fatty food }\end{array}$ & $\begin{array}{l}\text { Nausea and/ } \\
\text { or vomiting }\end{array}$ & $\begin{array}{c}\text { Mass in right } \\
\text { hypochondrium }\end{array}$ & & \\
\hline \multirow{5}{*}{ Diagnosis } & $\begin{array}{l}\text { Chronic } \\
\text { cholecystitis with } \\
\text { cholelithiasis }\end{array}$ & 749 & 34 & 23 & 0 & 806 & \multirow{6}{*}{$<0.001$} \\
\hline & $\begin{array}{l}\text { Acute cholecystitis } \\
\text { with mucocele }\end{array}$ & 9 & 3 & 4 & 0 & 16 & \\
\hline & $\begin{array}{l}\text { Acute cholecystitis } \\
\text { with empyema }\end{array}$ & 5 & 3 & 3 & 0 & 11 & \\
\hline & Polyp & 1 & 0 & 0 & 0 & 1 & \\
\hline & Malignancy & 2 & 0 & 1 & 3 & 6 & \\
\hline \multicolumn{2}{|l|}{ Total } & 766 & 40 & 31 & 3 & 840 & \\
\hline
\end{tabular}

Table-V. Presenting symptoms and diagnosis of patients

\begin{tabular}{|l|c|c|}
\hline & Frequency & Percent \\
\hline Chronic cholecystitis with cholelithiasis & 806 & 96.0 \\
\hline Acute cholecystitis with mucocele & 16 & 1.9 \\
\hline Acute cholecystitis with empyema & 11 & 1.3 \\
\hline Polyp & 1 & .1 \\
\hline Malignancy & 6 & .7 \\
\hline Total & 840 & 100.0 \\
\hline
\end{tabular}

Table-VI. Histopathological diagnosis $(n=840)$ 


\section{DISCUSSION}

In our study females were much more affected as compared to males with male to female ratio of $1: 10.6$, which is also reported in similar other studies. ${ }^{12,13}$ Although the mean age of $42.48 \pm 14.8$ years ranging from 13 to 87 years as reported by our study was higher than that in other studies. ${ }^{14}$

Approximately ninety one percent of the patients presented with the presenting complaint of pain in upper abdomen which is almost consistent with the study of Siddiqui et al. ${ }^{15}$ In our study none of the patients had neither any clinical evidence of malignancy nor any such picture was seen on radiological imaging.

The most common histopathological diagnosis was chronic cholecystitis with cholelithiasis in 806 patients $(96 \%)$ which was also seen in similar studies done by Siddiqui et al which also reported the same diagnosis in $92.3 \%$ of patients and by Memon ${ }^{16}$ in $64.8 \%$ of the cases.

In our study only one incidental case of gall bladder polyp was seen $(0.1 \%)$, which is a much lower incidence as compared to other studies which have an incidence ranging from 4.6 to $6.9 \% .{ }^{17}$ The polyp was found in a male as according to its greater prevalence present in males. ${ }^{18}$

Adenocarcinoma of gall bladder in our study was incidentally seen in six patients $(0.7 \%)$. No gross abnormality was seen in these gall bladders. However this incidence is quite low as compared to other studies which showed it varying from 6.9 to $12 \% .^{19,20}$ This may be due to the strict exclusion criteria of omitting the patients having pre operative provisional diagnosis of carcinoma gall bladder.

The carcinoma of gall bladder is strongly associated with gall stones in addition to presence of many other pre malignant conditions as well. ${ }^{19}$ Therefore due to the presence of this strong association it is very vital to pay attention to the histopathological reporting of all gall bladder specimens undergoing cholecystectomies for cholelithiasis irrespective of presence or absence of any abnormality present grossly. It has been widely seen that long standing gall stones may cause associated mucosal irritation causing cellular atypia, increased cellular proliferation and progression from hyperplasia and metaplasia to carcinoma in situ. ${ }^{21}$ Other studies have also confirmed the presence of such changes as a precursor to carcinoma of gall bladder. ${ }^{22}$

\section{CONCLUSION}

After review of the literature, it has been noted that many different opinions exist regarding examination of gall bladder specimens. It is very significant to do their routine histopathological examination even in the absence of any macroscopic abnormality which may be associated with carcinoma of gall bladder and may require further surgical intervention.

\section{CONFLICTS OF INTEREST}

There are no conflicts of interest.

\section{Copyright@ 12 Oct, 2019.}

\section{REFERENCES}

1. Agrawal S. Jonnalagadda S: Gallstones, from gallbladder to gut: Management options for diverse complications. Postgrad Med 2000, 108:143-53.

2. Huang J, Chang $\mathrm{CH}$, Wang JL, Kuo HK, Lin JW, Shau WY, et al. Nationwide epidemiological study of severe gallstone disease in Taiwan. BMC Gastroenterol. 2009; 9(1):63.

3. Rizvi TJ, Zuberi SJ. Risk factors for gall bladder cancer in Karachi. J Ayub Med Coll Abbottabad 2003; 15:16-8.

4. Underwood JCE: A recovery plan for histopathology. Royal Coll Path Bulletin 2001, 113:12-14.2.

5. Wilkinson DS: Carcinoma of the gall bladder: An experience and review of the literature. Aust $\mathrm{N} \mathrm{Z} \mathrm{J}$ Surg 1995, 65:724-727.

6. Samad A: Gall bladder carcinoma in patients undergoing cholecystectomy for cholelithiasis. J Pak Med Assoc 2005, 55:497-499.

7. Misra S, Chaturvedi A, Misra NC, Sharma ID. Carcinoma of the gallbladder. Lancet Oncol 2003; 4:167-76.

8. Lohana D et al. Frequency of gall bladder carcinoma in patients undergoing surgery for cholelithiasis. Isra Med J Apr 2009; 1(1):13-8. 
9. Inui K, Yoshino J, Miyoshi H: Diagnosis of gallbladder tumors. Intern Med 2011, 50(11):1133-1136.

10. Siddiqui FG, Soraya NS: An audit of cholecystectomy specimens. J Surg Pak 2002, 7:18-21.

11. Naqvi $\mathrm{SQH}$, et al. Frequency of carcinoma of gallbladder in patients with cholelithiasis. Gomal J Med Sci Jul-Dec 2005; 3(2): 41-3.

12. ChannaNA, Soomro AM, GhangroAB: Cholecystectomy is becoming an increasingly common operation in Hyderabad and adjoining areas. Rawal Med J 2007, 32(2):128-130.

13. Murshid KR: Symptomatic gallstones: A disease of young Saudi women. Saudi J Gastroenterol 1998, $4(3): 159-162$.

14. Ali SA, Tahir SM, Soomoro AG, Siddiqui AJ, Memon AS: Open cholecystectomy without intraperitoneal drainage. J Ayub Med Coll Abbottabad 2010, 22(2):29 31.

15. Siddiqui et al.: Routine histopathology of gallbladder after elective cholecystectomy for gallstones: waste of resources or a justified act? BMC Surgery 2013 13:26.

16. Memon W, Khanzada TW, Samad A, Kumar B: Histopathology sepectrum of gallbladder specimens after cholecystectomy. Pak J Med Sci 2011, 27(3):533536.
17. Matos AS, Baptista HN, Pinheiro C, Martinho F: [Gallbladder polyps: how should they be treated and when?]. Rev Assoc Med Bras 2010, 56(3):318-321.

18. Sun XJ, Shi JS, Han Y, Wang JS, Ren H: Diagnosis and treatment of polypoid lesions of the gallbladder: Report of 194 cases. Hepatobiliary Pancreat Dis Int 2004, 3(4):591-594.

19. Ayyaz M, Waris M, Fahim F: Presentation and etiological factors of cancer gall bladder in patients undergoing cholecystectomies at Mayo Hospital, Lahore. Ann King Edward Med Coll 2001, 7:138-140.

20. Nawaz T, Khan RA, Malik AZ, Anwar I, Younus M: Incidence of carcinoma gall bladder in cholelithiasis. Pak J Surg 2000, 16:33-36.

21. Duarte I, Llanos O, Domke H, Harz C, Valdivieso V: Metaplasia and precursor lesions of gallbladder carcinoma. Frequency, distribution, and probability of detection in routine histologic samples. Cancer 1993, 72(6):1878-1884.

22. Sarma NH, Ramesh K, Gahukamble LD, Fituri OM, Mangal DK: Gall bladder cancer in north eastern Libya. East Afr Med J 1998, 75(7):417-421.

\begin{tabular}{|c|c|c|c|}
\hline \multicolumn{4}{|c|}{ AUTHORSHIP AND CONTRIBUTION DECLARATION } \\
\hline Sr. \# & Author(s) Full Name & Contribution to the paper & Author(s) Signature \\
\hline 2 & $\begin{array}{l}\text { Sadaf Shafique } \\
\text { Raheel Khan } \\
\text { Raees Abbas }\end{array}$ & $\begin{array}{l}\text { Conception \& design, } \\
\text { acquisition of data, analysis \& } \\
\text { interpretation of data. } \\
\text { Conception \& design, } \\
\text { acquisition of data, analysis \& } \\
\text { interpretaion of data. } \\
\text { Drafting the article. }\end{array}$ & Het \\
\hline 4 & Bakhtawer Mehmood & $\begin{array}{l}\text { Revising it critically for } \\
\text { important intellectual content. }\end{array}$ & 4 \\
\hline
\end{tabular}

